\title{
DEVELOPMENTAL AND NEUROLOGIC EFFECTS OF ALPHA-STAT VERSUS PH-STAT STRATEGIES FOR DEEP HYPOTHERMIC CARDIOPULMONARY BYPASS IN INFANTS
}

David C. Bellinger, PhD, MSc ${ }^{\mathrm{a}}$

David Wypij, PhD

Adre J. du Plessis, MBChB, MPH ${ }^{\mathrm{a}}$

Leonard A. Rappaport, $\mathrm{MD}^{\mathrm{b}}$

James Riviello, MD

Richard A. Jonas, $\mathrm{MD}^{\mathrm{c}}$

Jane W. Newburger, MD, MPH ${ }^{\mathrm{d}}$
Objectives: In a randomized single-center trial, we compared developmental and neurologic outcomes at 1 and 2 to 4 years of age in children who underwent reparative cardiac operations at less than 9 months of age after use of the alpha-stat versus $\mathrm{pH}$-stat strategy during deep hypothermic cardiopulmonary bypass.

Methods: Among 168 children eligible for follow-up, 1-year developmental evaluations were carried out on 111 , neurologic evaluations on 110 , and electroencephalographic evaluations on 102. Parents of 122 children completed questionnaires on behavior and development when children were 2 to 4 years of age.

Results: The Psychomotor Development Index scores of the alpha-stat and pH-stat groups did not differ significantly $(P=.97)$. For Mental Development Index scores, the treatment group effect differed according to diagnosis $(P=.007)$. In the D-transposition of the great arteries $(\mathrm{n}=59)$ and tetralogy of Fallot $(\mathrm{n}=36)$ subgroups, the $\mathrm{pH}$-stat group had slightly higher Mental Development Index scores than the alpha-stat group, although these differences were not statistically significant. In the ventricular septal defect subgroup $(\mathrm{n}=16)$, the alpha-stat group had significantly higher scores. Psychomotor Development Index and Mental Development Index scores were significantly higher in the group with D-transposition of the great arteries than in the other 2 groups $(P=.03$ and $P=.01$, respectively). Across all diagnoses, Mental Development Index scores were significantly higher than Psychomotor Development Index scores $(P<.001)$. Treatment group assignment was not significantly associated with abnormalities on neurologic examination $(P=.70)$ or electroencephalographic examination $(P=.77)$ at 1 year or with parents' ratings of children's development $(P=.99)$ or behavior $(P=.27)$ at age 2 to 4 years.

Conclusions: Use of alpha-stat versus $\mathrm{pH}$-stat acid-base management strategy during reparative infant cardiac operations with deep hypothermic cardiopulmonary bypass was not consistently related to either improved or impaired early neurodevelopmental outcomes. (J Thorac Cardiovasc Surg 2001;121:374-83)
From the Departments of Neurology, ${ }^{\mathrm{a}}$ Medicine, ${ }^{\mathrm{b}}$ Cardiovascular Surgery, ${ }^{\mathrm{c}}$ and Cardiology, ${ }^{\mathrm{d}}$ Children's Hospital; the Departments of Neurology, Pediatrics, and Surgery, Harvard Medical School; and the Department of Biostatistics, ${ }^{\mathrm{e}}$ Harvard School of Public Health, Boston, Mass.

Received for publication May 5, 2000; revisions requested Aug 1, 2000; revisions received Aug 18, 2000; accepted for publication Aug 31, 2000.

Supported by grants HL41786 and RR02172 from the National Institutes of Health.

Address for reprints: David C. Bellinger, PhD, MSc, Neuroepidemiology Unit, CA-503, Children's Hospital, 300 Longwood Ave, Boston, MA 02115.

Copyright (C) 2001 by The American Association for Thoracic Surgery

0022-5223/2001 $\$ 35.00+0 \quad \mathbf{1 2 / 1 / 1 1 1 2 0 6}$

doi: $10.1067 / \mathrm{mtc} .2001 .111206$
Arterial carbon dioxide tension $\left(\mathrm{PCO}_{2}\right)$ is one of the Amost important regulatory factors known to affect the level of cerebral blood flow during cardiopulmonary bypass (CPB), yet the optimal approach to $\mathrm{pH}$ management during hypothermic $\mathrm{CPB}$ and circulatory arrest remains controversial. ${ }^{1,2}$ In adult patients undergoing $\mathrm{CPB}$, neurologic outcomes appear to be better with the alpha-stat strategy, in which arterial $\mathrm{PCO}_{2}$ is maintained at $40 \mathrm{~mm} \mathrm{Hg}$ when the sample is measured at $37^{\circ} \mathrm{C}$ and is not corrected for the patient's temperature. ${ }^{3}$ In contrast, neurologic outcomes in infants may be better with the $\mathrm{pH}$-stat strategy, in which the arterial $\mathrm{PCO}_{2}$ is adjusted to $40 \mathrm{~mm} \mathrm{Hg}$ to maintain a $\mathrm{pH}$ of 7.40 at the patient's hypothermic temperature. Retrospective analyses of 
postbypass neurologic morbidity after a shift from the $\mathrm{pH}$-stat to alpha-stat method suggested that the incidence of choreoathetosis was higher, ${ }^{4}$ and psychometric intelligence in infants with transposition of the great arteries was lower when the alpha-stat strategy was used in conjunction with circulatory arrest. ${ }^{5}$ In a recent single-center clinical trial, children who underwent deep hypothermic cardiac operations with or without circulatory arrest, involving random assignment to alpha-stat or $\mathrm{pH}$-stat, $\mathrm{pH}$-stat was associated with lower postoperative morbidity, including fewer deaths $(P=.058)$, fewer electroencephalographic seizures $(P=.11)$, and faster recovery of electroencephalographic (EEG) activity $(P=.03) .{ }^{6}$ In addition, among the subgroup of patients with D-transposition of the great arteries (D-TGA), those assigned to the $\mathrm{pH}$-stat group experienced less frequent postoperative acidosis $(P=.02)$ or hypotension $(P=.05)$ and required a shorter duration of mechanical ventilation $(P=.01)$ and intensive care unit stay $(P=.01)$. To determine the longer term implications of these perioperative treatment group differences, we assessed these children at age 1 year with respect to their neurologic and developmental status by means of in-person evaluations. Their development was evaluated again when the children were 2 to 4 years of age by means of parent-completed questionnaires.

\section{Methods}

Enrollment of patients. Eligibility criteria included a reparative heart operation at age less than 9 months for diagnoses, including D-TGA with intact ventricular septum or ventricular septal defect (VSD), tetralogy of Fallot (TOF), TOF with pulmonary atresia, VSD, complete common atrioventricular canal defect (CAVC), truncus arteriosus, or total anomalous pulmonary venous return. Exclusion criteria included birth weight less than $2.25 \mathrm{~kg}$, associated congenital or acquired extracardiac disorders of greater than minor severity, and a previous cardiac operation.

Between July 1992 and July 1996, 216 infants were determined to be eligible. The parents of $26(12 \%)$ infants declined to participate. Of the 190 patients enrolled, 8 (4\%) were excluded post hoc because their operation was not performed under deep hypothermia (tympanic temperature $\leq 18^{\circ} \mathrm{C}$ ), resulting in a final sample of 182 infants. Informed consent was obtained from the parents of all infants.

Study design. The design was a prospective, randomized, single-center trial.

Immediately before the operation, infants were randomly assigned, by means of a permuted blocks design, to receive a $\mathrm{pH}$ management strategy of either $\mathrm{pH}$-stat or alpha-stat, with stratification according to surgeon, diagnosis, and age group ( $<1$ month, 1-4 months, and 5-9 months). Surgeons and anesthesiologists were kept unaware of the interim results during the study. All individuals responsible for evaluating patient outcomes were blinded to treatment assignment. Information on extracorporeal perfusion and anesthesia methods and on postoperative hemodynamic status is presented elsewhere. ${ }^{6}$

Developmental testing. When children were approximately 1 year old, the Bayley Scales of Infant Development were administered. ${ }^{7}$ These yield 2 standardized scores: the Psychomotor Development Index (PDI) and the Mental Development Index (MDI). For each index, we calculated the proportion of children whose scores were less than 80 , which is approximately $2 \mathrm{SDs}$ below the contemporary mean scores on the 1969 version of this test (112 and 111 , respectively). ${ }^{8}$ We calculated the proportions of children who passed 3 items on the motor scale that represent major milestones: neat pincer grasp, pat-a-cake: midline skills, and walks alone. In addition, scores in specific developmental domains were derived by using the item analysis scheme of Kohen-Raz' eye-hand coordination, manipulation, object relations, imitation, and vocalization.

When children were between 2 and 4 years of age, parents were mailed 2 questionnaires to complete. The Child Development Inventory ${ }^{10}$ yields the following scores: social, self help, gross motor, fine motor, expressive language, language comprehension, letters, numbers, and general development. The Child Behavior Checklist $2 / 3^{11}$ consists of 3 broadband scales (total behavior problems, internalizing, and externalizing) and 6 narrow-band scales (social withdrawal, depressed, sleep problems, somatic problems, aggressive, and destructive).

Neurologic examination. Neurologic examinations were performed by a single pediatric neurologist when the children were 1 year of age by means of a 41-item format with ageappropriate items selected from those used in previous studies. ${ }^{12-15}$ Findings were classified as normal or abnormal. Abnormalities were subclassified into 5 categories: head circumference, mental status, special senses (visual and auditory), cranial nerve motor function (oculomotor, facial, and oromotor), and peripheral motor function (strength, tone, and tendon reflexes). An infant's overall evaluation was classified as abnormal if a definite abnormality was found in any of these 5 areas.

EEG examination. EEG data were recorded when the children were 1 year of age by means of a 16-channel video electroencephalograph (Telefactor; Modac, West Conshohocken, Pa). Electrodes were placed according to the standard 10-20 system of electrode placement. The EEG data were interpreted by a child neurologist board certified in electroencephalography. Recordings extended over at least 40 minutes and included wakefulness, drowsiness, and natural or sedated (chloral hydrate) sleep.

The recordings were interpreted by means of standard agespecific criteria for EEG background during wakefulness and sleep. Background abnormality was defined as dysmaturity, abnormal sleep-wake cycling, asymmetry of amplitude or frequency, diffuse low voltage or frequency, or a burst-suppression pattern. In addition, any paroxysmal activity in the form of spike or sharp discharges was noted. Electrographic seizures were defined as rhythmic discharges that evolved and lasted for 10 seconds or more. 
Table I. Characteristics of children for whom 1-year developmental data or 2- to 4-year questionnaires are available, according to treatment group

\begin{tabular}{|c|c|c|}
\hline & Alpha-stat $(n=74)$ & pH-stat $(n=79)$ \\
\hline \multicolumn{3}{|l|}{ Preoperative characteristics } \\
\hline Birth weight $(\mathrm{kg})$ & $3.40 \pm 0.58$ & $3.44 \pm 0.51$ \\
\hline Gestational age (wk) & $39.5 \pm 1.4$ & $39.6 \pm 1.4$ \\
\hline Apgar score (5 min) & $8.2 \pm 1.2$ & $8.6 \pm 0.6$ \\
\hline Age at operation (d), median (range) & $8.5(1-261)$ & $6(1-222)$ \\
\hline Sex (\% male) & 69 & 59 \\
\hline Race (\% nonwhite) & 8 & 11 \\
\hline \multicolumn{3}{|l|}{ Diagnosis group, $\mathrm{n}(\%)$} \\
\hline D-TGA & $36(49)$ & $44(56)$ \\
\hline TOF/other & $27(36)$ & $26(33)$ \\
\hline VSD/CAVC & $11(15)$ & $9(11)$ \\
\hline \multicolumn{3}{|l|}{ Operative characteristics } \\
\hline $\mathrm{pH}\left(\right.$ at $\left.37^{\circ} \mathrm{C}\right)$ at onset of circulatory arrest or low-flow bypass & $7.41 \pm 0.05$ & $7.14 \pm 0.05$ \\
\hline $\mathrm{PCO}_{2}$ at onset of circulatory arrest or low-flow bypass $(\mathrm{mm} \mathrm{Hg})$ & $40 \pm 6$ & $91 \pm 13$ \\
\hline Total support time (min) & $124 \pm 38$ & $126 \pm 40$ \\
\hline Total bypass time (min) & $103 \pm 41$ & $106 \pm 38$ \\
\hline Duration of circulatory arrest (min) & $21 \pm 16$ & $20 \pm 17$ \\
\hline None, $\mathrm{n}(\%)$ & $11(15)$ & $9(11)$ \\
\hline $1-10$ & $17(23)$ & $27(34)$ \\
\hline $11-30$ & $19(26)$ & $19(24)$ \\
\hline $31-44$ & $22(30)$ & $17(22)$ \\
\hline$\geq 45$ & $5(7)$ & $7(9)$ \\
\hline \multicolumn{3}{|l|}{ Postoperative neurologic outcomes } \\
\hline Definite clinical seizures (\%) & 4 & 3 \\
\hline Ictal activity within $48 \mathrm{~h}$ after operation (\%) & 9 & 2 \\
\hline \multicolumn{3}{|l|}{ Follow-up data at $1 \mathrm{y}$} \\
\hline Age (mo) & $13.4 \pm 1.5$ & $13.1 \pm 1.0$ \\
\hline Weight (z-score) & $-0.49 \pm 1.18$ & $-0.34 \pm 1.15$ \\
\hline Length (z-score) & $-0.94 \pm 1.47$ & $-0.49 \pm 1.18$ \\
\hline Social class* & $41 \pm 14$ & $43 \pm 14$ \\
\hline Parental intelligence quotient $\dagger$ & $98 \pm 15$ & $94 \pm 17$ \\
\hline
\end{tabular}

Values are means $\pm \mathrm{SD}$.

*Score on the Hollingshead Four-Factor Index of Social Studies, ${ }^{16}$ with higher scores indicating higher social status.

$\dagger$ Score on the Peabody Picture Vocabulary Test (revised). ${ }^{17}$

Statistical analyses. Treatment group comparisons were conducted by means of intention-to-treat analyses. Diagnoses were grouped in the following way: D-TGA (D-TGA/intact ventricular septum and D-TGA/VSD); TOF/other (TOF or TOF with pulmonary atresia, truncus arteriosus, or total anomalous pulmonary venous return); and VSD/CAVC. On the basis of our previous work, PDI was designated as the primary outcome. All hypothesis tests of outcome variables were adjusted for diagnosis group (D-TGA, TOF/other, and VSD/CAVC). Treatment by diagnosis group interaction terms was evaluated. If an interaction was significant, separate $P$ values were calculated for the effect of treatment for each diagnosis group. Outcomes included both continuous and categoric variables. Multiple linear regression methods and Wilcoxon rank-sum tests were used to analyze continuous outcome variables. Fisher exact tests and multiple logistic regression methods were used to analyze categoric outcome variables. All $P$ values are 2 -tailed.

Analyses of the 3 summary scales of the Child Behavior Checklist (total problem behaviors, internalizing, and externalizing) were based on $\mathrm{T}$ scores, for which the expected means $\pm \mathrm{SD}$ are $50 \pm 10$. T scores for the narrow-band scales of the Child Behavior Checklist are typically severely skewed because all raw scores above the 69th percentile are assigned a $\mathrm{T}$ score of 50 . Therefore, analyses were performed on raw scores, which were more normally distributed.

Of the 182 children enrolled in the study, 4 died within 1 month of their operation (all with D-TGA and assigned to the alpha-stat group). Ten families were not considered eligible for follow-up because of a language barrier $(n=5)$ or because of residence outside of the United States $(n=5)$. Of the remaining 168 children, the 122 living in New England or New York were contacted about returning for the follow-up evaluations of children at 1 year of age. Of these, 102 (84\%) were evaluated. The remainder had scheduling problems or were lost to follow-up. We also evaluated 9 (20\%) of the 46 children who resided elsewhere but whose families informed us that they would be traveling to the Boston area. In-person developmental examinations at the age of 1 year were thus completed for 111 children (54 alpha-stat and $57 \mathrm{pH}$-stat). The numbers of children in the 3 diagnosis groups for whom 


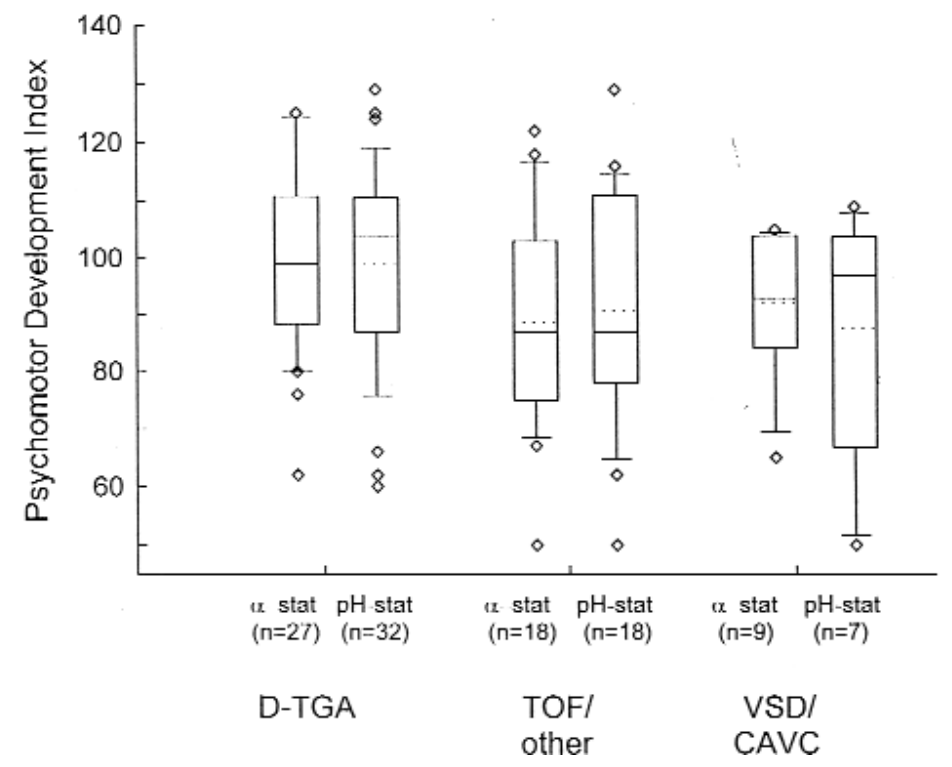

Fig 1. Box plots of Psychomotor Development Index scores stratified by treatment group (alpha-stat vs $\mathrm{pH}$-stat) and diagnosis group (D-TGA, TOF/other, and VSD/CAVC). Within a box, the solid bar represents the median value, the dashed line represents the mean value, the upper boundary of the closed box represents the 75th percentile, and the lower boundary of the closed box represents the 25 th percentile. The vertical lines extend to the 10th and 90th percentiles, with more extreme observations plotted as diamonds.

Table II. Developmental outcomes at 1 year, according to treatment group

\begin{tabular}{lccc}
\hline & Alpha-stat $(n=54)$ & pH-stat $(n=57)$ & P value* \\
\hline Bayley Scales of Infant Development & & & .97 \\
PDI & $94.5 \pm 17.4$ & $95.0 \pm 19.5$ & 1.00 \\
PDI score $\leq 80(\%)$ & 20 & & \\
Selected motor scale items (\% passing) & 91 & 91 & 1.00 \\
$\quad$ Neat pincer grasp & 78 & 77 & 1.00 \\
Pat-a-cake: midline & 59 & 60 & 1.00 \\
$\quad$ Walks alone & $103.8 \pm 17.5$ & $105.9 \pm 16.0$ & $.26, .22, .006 \dagger$ \\
MDI & 11 & 7 & .52 \\
MDI score $\leq 80(\%)$ & $13.0 \pm 2.0$ & $13.0 \pm 1.5$ & .45 \\
Kohen-Raz subscales & $8.7 \pm 0.6$ & $8.6 \pm 0.8$ & $.57, .09, .001 \dagger$ \\
Eye-hand coordination & $8.6 \pm 0.7$ & $8.6 \pm 0.8$ & $.33, .46, .003 \dagger$ \\
Manipulation & $6.2 \pm 2.0$ & $5.9 \pm 1.7$ & .90 \\
Object relations & $6.5 \pm 2.0$ & $6.2 \pm 1.8$ & .62 \\
Imitation & 37 & 30 & .43 \\
Vocalization & & \\
lMDI-PDIl $<17.3(\%)$ & & \\
\hline
\end{tabular}

Values are means \pm SD.

*Linear regression $P$ value for the effect of treatment, with adjustment for diagnosis group and social class for continuous outcomes and Fisher exact $P$ value for the effect of treatment for dichotomous outcomes. Models for Kohen-Raz subscales also adjust for age at developmental testing.

$\dagger$ Because of a significant $(P<.01)$ treatment by diagnosis group interaction, separate $P$ values for the effect of treatment are reported for the D-TGA, TOF/other, and $\mathrm{VSD} / \mathrm{CAVC}$ diagnosis groups, respectively.

developmental evaluations were completed were as follows: D-TGA, 59; TOF/other, 36; and VSD/CAVC, 16. Neurologic and EEG examinations at age 1 year were completed for 109 and 102 children, respectively. Across the entire sample, the age $($ mean $\pm \mathrm{SD})$ at follow-up evaluation was $13.2 \pm 1.3$ months.
The families of all eligible children were asked to complete the questionnaires on child development and behavior. One child with TOF assigned to the alpha-stat group died suddenly at age 15 months and was found, on postmortem examination, to have congenital stenosis of the left coronary ostium. One or more completed questionnaires were received for 122 
(73\% of those to whom questionnaires were sent) children. Completed Child Development Inventory forms were received for 121 children, and completed Child Behavior Checklist 2/3 forms were received for 117 children. Among the children for whom questionnaires were received, the age (mean $\pm \mathrm{SD}$ ) was $35.4 \pm 6.5$ months. Overall, either evaluations at 1 year of age or parent-completed questionnaires at 2 to 4 years of age were available for $153(91 \%)$ of 168 eligible children.

\section{Results}

Table $\mathrm{I}^{16,17}$ presents the demographic and medical characteristics of families who participated in the developmental evaluations of the children at 1 year of age or who completed at least one of the questionnaires on the children's development at 2 to 4 years of age. Treatment groups were similar in terms of the preoperative history and the incidence of preoperative abnormalities on neurologic examination or EEG. Although treatment groups were, by design, equivalent in terms of the distribution of diagnoses, the D-TGA and TOF/other groups were considerably larger than the VSD/CAVC group. One infant in the $\mathrm{pH}$-stat group had a preoperative seizure. The age at operation (mean \pm $\mathrm{SD})$ was younger in the D-TGA group ( $5 \pm 3$ days $)$ than in the TOF/other group $(79 \pm 69$ days $)$ or the VSD/CAVC group (119 \pm 59 days $)$.

The treatment groups were similar in intraoperative perfusion variables, including duration of circulatory arrest, total bypass time, and total support time (Table I), although total support time (mean \pm SD) was greater among patients in the D-TGA group ( $149 \pm 32$ minutes) than in the TOF/other $(99 \pm 28$ minutes $)$ or VSD/CAVC (97 \pm 27 minutes) groups. The duration of circulatory arrest (mean \pm SD) was $19.7 \pm 14.4$ minutes in the DTGA group, $24.6 \pm 17.0$ minutes in the TOF/other group, and $13.9 \pm 17.8$ minutes in the VSD/CAVC group. Approximately one third of the patients in each group had total circulatory arrest periods of more than 30 minutes. As expected, $\mathrm{pH}$ was significantly lower and $\mathrm{PCO}_{2}$ significantly higher in the $\mathrm{pH}$-stat group than in the alpha-stat group throughout the bypass period. As reported previously, ${ }^{6}$ EEG seizures in the postoperative period were more frequent among patients in the alpha-stat group $(P=.11)$.

Children for whom some follow-up data were available did not differ significantly from those for whom such data were not available in terms of family characteristics (social class and ethnicity), neonatal status (gestational age and 5-minute Apgar score), age at operation, operative characteristics (total support time and lowest $\mathrm{PCO}_{2}$ ), or postoperative course (intensive care unit days, days intubated, days of hospitalization, and clinical or EEG seizures). Birth weight was the only variable on which groups differed significantly, with the children for whom follow-up data were available being slightly heavier $(P=.04)$.

\section{Assessments at 1 year of age}

Bayley Scales of Infant Development. Although the PDI score (mean \pm SD) in the D-TGA group $(99.0 \pm$ 16.8) was significantly higher than the mean scores in either the TOF/other $(89.7 \pm 19.8)$ or VSD/CAVC $(90.3$ \pm 18.3 ) groups $(P=.03)$, PDI scores did not differ by treatment group (Table II and Fig 1). The scores of the alpha-stat and pH-stat groups were similar within each diagnostic group. The proportions of children achieving scores of 80 or less (ie, at least 2 SDs below the population mean) were increased relative to expectation but did not differ between treatment groups (20\% in the alpha-stat group vs $21 \%$ in the $\mathrm{pH}$-stat group). The frequencies of such scores in the D-TGA, TOF/other, and VSD/CAVC groups were 14\%, 31\%, and $25 \%$, respectively. Treatment groups did not differ in the proportions of children who passed the following items from the motor scale: neat pincer grasp, pat-acake: midline skill, and walks alone.

MDI score (mean $\pm \mathrm{SD}$ ) was significantly higher in the D-TGA group $(109.4 \pm 14.7)$ than in either the TOF/other $(100.3 \pm 15.6)$ or VSD/CAVC groups $(98.9 \pm$ 22.0, $P=.01)$. The treatment group by diagnosis group interaction was significant $(P=.007$, Table II and Fig 2$)$. Among children in the VSD/CAVC group, assignment to alpha-stat was associated with significantly higher scores (22.2-point difference, $P=.006$ ), although the numbers of patients in the 2 treatment groups were small (9 in the alpha-stat group and 7 in the $\mathrm{pH}$-stat group). In this diagnosis group assignment to alpha-stat was also associated with significantly higher scores on the manipulation $(P=.001)$ and object relations $(P=.003)$ subscales. Within both the D-TGA and TOF/other subgroups, children assigned to $\mathrm{pH}$-stat tended to achieve higher MDI scores than children assigned to alpha-stat (4.7 and 6.4 points, respectively). These differences did not achieve statistical significance, however. Overall, the proportions of children whose MDI scores were 80 or less were similar in the alpha-stat and $\mathrm{pH}$-stat groups (11\% and $7 \%$, respectively). The frequencies of such scores in the D-TGA, TOF/other, and VSD/CAVC groups were $3 \%, 14 \%$, and $19 \%$, respectively.

In the cohort as a whole, the mean PDI score was significantly lower than the mean MDI score (10.2-point difference, $P<.001)$. Therefore, for substantial proportions of children in each group (37\% in the alpha-stat group and $33 \%$ in the $\mathrm{pH}$-stat group), the MDI-PDI discrepancy exceeded the value that corresponds to the .05 level of significance (17.3 points). The percentage did 


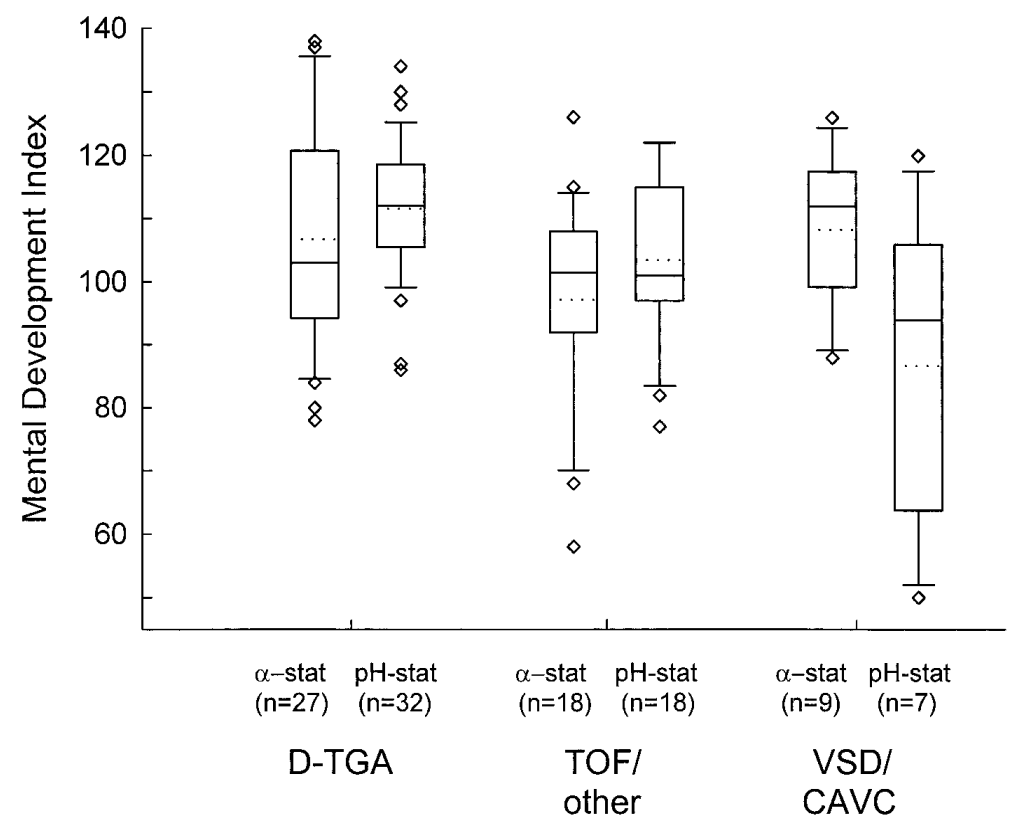

Fig 2. Box plots of Mental Development Index scores stratified by treatment group (alpha-stat vs pH-stat) and diagnosis group (D-TGA, TOF/other, and VSD/CAVC). Within a box, the solid bar represents the median value, the dashed line represents the mean value, the upper boundary of the closed box represents the 75 th percentile, and the lower boundary of the closed box represents the 25th percentile. The vertical lines extend to the 10th and 90th percentiles, with more extreme values plotted as diamonds.

Table III. Neurologic outcomes at 1 year, according to treatment group

\begin{tabular}{|c|c|c|c|}
\hline & Alpha-stat $(n=53)$ & $p H$-stat $(n=57)$ & $\mathrm{P}$ value* \\
\hline Head circumference & & & 1.00 \\
\hline Normal $(\%)$ & 89 & 89 & \\
\hline Microcephalic & 8 & 9 & \\
\hline Macrocephalic & 4 & 2 & \\
\hline Mental status (\% abnormal) & 0 & 0 & 1.00 \\
\hline Special senses ( $\%$ abnormal) & 0 & 0 & 1.00 \\
\hline Cranial nerves (\% abnormal) & 8 & 11 & .74 \\
\hline Motor function & & & .84 \\
\hline Normal (\%) & 70 & 72 & \\
\hline Weak, global & 2 & 4 & \\
\hline Weak, extremities only & 2 & 4 & \\
\hline Abnormal tone, tendon reflexes, or both & 26 & 21 & \\
\hline Overall evaluation ( $\%$ any abnormality) & 42 & 37 & .70 \\
\hline
\end{tabular}

*Fisher exact $P$ value for the effect of treatment.

not differ across treatment groups, however. Similar trends were seen in each diagnostic group.

In analyses adjusting for treatment group and diagnosis group, the duration of total circulatory arrest was not significantly associated with MDI $(P=.67)$ or PDI $(P=.60)$ scores.

Neurologic examination. The proportions of children in each treatment group considered to have an abnormal neurologic examination were substantial, although not significantly different ( $42 \%$ in the alpha-stat group and $39 \%$ in the $\mathrm{pH}$-stat group, respectively; $P=.70$; Table III). Similarly, no treatment group differences were found with respect to specific types of abnormalities. The most common findings in both groups were abnormal muscle tone (usually decreased tone), increased tendon reflexes, persistent primitive reflexes, abnormal gait, abnormal facial motor and oromotor function, and microcephaly. 
Table IV. Developmental outcomes at 2 to 4 years, according to treatment group

\begin{tabular}{|c|c|c|c|}
\hline & Alpha-stat & pH-stat & $\mathrm{P}$ value* \\
\hline Child Development Inventory $\dagger$ & $(\mathrm{n}=58)$ & $(\mathrm{n}=63)$ & \\
\hline Social & $31 \pm 7$ & $30 \pm 7$ & .34 \\
\hline Self help & $26 \pm 6$ & $25 \pm 8$ & .76 \\
\hline Gross motor & $22 \pm 5$ & $22 \pm 5$ & .24 \\
\hline Fine motor & $19 \pm 4$ & $19 \pm 5$ & .16 \\
\hline Expressive language & $38 \pm 11$ & $35 \pm 12$ & .35 \\
\hline Language comprehension & $38 \pm 10$ & $35 \pm 11$ & .31 \\
\hline Letters & $2 \pm 3$ & $2 \pm 3$ & .85 \\
\hline Numbers & $6 \pm 3$ & $6 \pm 3$ & .88 \\
\hline General development & $45 \pm 11$ & $44 \pm 12$ & .99 \\
\hline Child Behavior Checklist $\$$ & $(\mathrm{n}=55)$ & $(\mathrm{n}=62)$ & \\
\hline Total problem behaviors (T scores) & $48 \pm 11$ & $49 \pm 10$ & .27 \\
\hline \multicolumn{4}{|l|}{ Broad-band scales (T scores) } \\
\hline Internalizing & $45 \pm 10$ & $48 \pm 9$ & .07 \\
\hline Externalizing & $48 \pm 10$ & $49 \pm 9$ & .65 \\
\hline \multicolumn{4}{|l|}{ Narrow-band scales (raw scores) } \\
\hline Social withdrawal & $2.7 \pm 2.7$ & $2.8 \pm 2.6$ & .66 \\
\hline Depressed & $3.1 \pm 2.7$ & $4.1 \pm 2.7$ & .01 \\
\hline Sleep problems & $2.8 \pm 2.7$ & $3.3 \pm 3.0$ & .17 \\
\hline Somatic problems & $2.6 \pm 2.6$ & $3.0 \pm 2.7$ & .41 \\
\hline Aggressive & $7.9 \pm 5.6$ & $7.9 \pm 5.5$ & .82 \\
\hline Destructive & $3.6 \pm 2.9$ & $3.6 \pm 2.8$ & .68 \\
\hline
\end{tabular}

Values are means \pm SD.

* Linear regression $P$ value for the effect of treatment, with adjustment for diagnosis group and social class. Models for Child Development Inventory scales also adjusts for age when parents completed a questionnaire.

$\dagger$ Higher scores on the Child Development Inventory reflect better development.

$\ddagger$ Higher scores on the Child Behavior Checklist reflect more severe problem behaviors.

EEG examination. Unequivocal abnormal features on EEG were identified in 13 (13\%) of the 102 infants studied (7 in the alpha-stat group and 6 in the pH-stat group). In 8 infants ( 3 in the alpha-stat group and 5 in the $\mathrm{pH}$-stat group), a significant asymmetry between the 2 hemispheres was noted in the amplitude, frequency, or both of the EEG background. In 7 infants (5 in the alpha-stat group and 2 in the $\mathrm{pH}$-stat group), an excess of paroxysmal spike or sharp wave activity indicating cortical irritability was found. No infants showed evidence of dysmaturity or electrographic seizure activity. The 2 treatment groups did not differ significantly on any abnormality determined by EEG examination $(P=.77)$ or on any specific EEG end points.

\section{Assessments at 2 to 4 years of age}

Child Development Inventory. Treatment groups did not differ significantly on any Child Development Inventory scale (Table IV), including general development $(P=.99)$.

Child Behavior Checklist 2/3. In the cohort as a whole, the mean scores on 1 broad-band scale (internalizing) and 2 narrow-band scales (social withdrawal and depressed) were significantly lower $(P<.005)$ than normative values. Treatment groups did not differ sig- nificantly on the total problem behaviors scale $(P=.27)$. Depressed was the only one of the 3 broadband and 6 narrow-band scales on which a significant treatment group difference was found. Children in the $\mathrm{pH}$-stat group had higher (ie, less optimal) scores than children in the alpha-stat group $(P=.01$, Table IV).

\section{Discussion}

Neurocognitive morbidity can be documented in the majority of adults undergoing cardiac operations, although long-term sequelae are usually mild. ${ }^{18,19} \mathrm{In}$ children with congenital heart disease who have undergone cardiac operations, cognitive deficits are also common, but maturational changes, together with multiple preoperative and postoperative risk factors, make it difficult to ascertain the extent to which these are strictly attributable to intraoperative events. The risk of brain injury related to CPB in infants and children may be influenced by many variables, including the duration of total support, the depth of hypothermia, the rate and duration of core cooling, the degree of hemodilution, the duration of total circulatory aarrest, the type of oxygenator (bubble vs membrane), the use of arterial filtration, and aspects of the biochemical milieu, 
including the type of $\mathrm{pH}$ management chosen during core cooling (alpha-stat vs pH stat). ${ }^{20,21}$

We previously demonstrated that the use of the $\mathrm{pH}$ stat strategy in infants undergoing deep hypothermic $\mathrm{CPB}$ was associated with a trend toward lower postoperative morbidity and with a significantly shorter recovery time to first EEG activity. ${ }^{6}$ The current study explored the effect of $\mathrm{pH}$ management strategy on longer term developmental outcome in the same study cohort. We found that infants randomized to the $\mathrm{pH}$-stat and alpha-stat methods of $\mathrm{pH}$ management did not differ significantly at 1 year of age in their scores on the Bayley Scales of Infant Development or in their neurologic examination. Similarly, at 2 to 4 years of age, the treatment groups had similar development, as assessed by parental responses to mailed questionnaires, including the Child Development Inventory and the Child Behavior Checklist.

During the perioperative phase of the study, randomization was stratified within 3 overall diagnostic groups: D-TGA, TOF/other, and VSD/CAVC. For children with D-TGA and conotruncal defects (TOF/other), there was a trend toward better developmental outcome among those in the $\mathrm{pH}$-stat group, but for patients with VSD/CAVC, outcome was significantly worse among those assigned to the $\mathrm{pH}$-stat strategy. The number of patients in each diagnosis group was relatively small, however. Furthermore, because of the association of diagnosis with age at operation, we could not determine which factor was responsible for the apparent differences in the effect of $\mathrm{pH}$ management strategy in these groups. Overall, neurodevelopmental outcome was best among patients with D-TGA and weakest among those who had undergone repair of ventricular septal defects. The especially poor outcomes of those in the $\mathrm{VSD} / \mathrm{CAVC}$ group randomized to the $\mathrm{pH}$-stat strategy should be noted.

Previous studies on the effect of acid-base management strategy during use of deep hypothermic CPB in infants and children have suggested that the acidotic pH-stat strategy, compared with the more alkalotic alpha-stat strategy, may provide a greater degree of central nervous system protection. In a retrospective review, children with D-TGA who had undergone the Senning procedure under alpha-stat conditions showed worse neurodevelopmental outcome than those managed by pH-stat. ${ }^{5}$ Of note, however, the operative management of the retrospective study cohort, whose operations were performed between 1983 and 1988, differed in many respects from that used in the present study. Another retrospective review observed that the incidence of postoperative choreoathetosis became greater after the institution of the alpha-stat strategy. ${ }^{4}$ In the neonatal piglet $\mathrm{pH}$ stat was associated with better preservation of cellular oxygen delivery and improved recovery of cerebral high-energy phosphates and intracellular $\mathrm{pH}$ during reperfusion..$^{22,23}$ Finally, during the perioperative phase of the current prospective randomized trial, use of the $\mathrm{pH}$-stat strategy in infants undergoing deep hypothermic CPB was associated with a trend toward lower postoperative morbidity, shorter recovery time to first EEG activity, and, in patients with DTGA, shorter duration of intubation and intensive care unit stay. ${ }^{6}$ At intermediate follow-up in this cohort, infants with D-TGA and TOF/other tended to have higher median scores on the PDI and MDI, but this study did not have sufficient statistical power within these subgroups to achieve statistical significance. Comparisons of our results with those of previous studies of acid-base management strategies must take account of the many recent advances in perfusion methods, including the addition of an arterial line filter, an improved membrane oxygenator with decreased priming volume, and the avoidance of prolonged periods of circulatory arrest. Coincident with these changes, for example, the incidence of perioperative seizures has greatly declined among children undergoing cardiac surgery at Boston Children's Hospital.

The present study should be interpreted in light of several limitations. In contrast to studies such as the Boston Circulatory Arrest Study, ${ }^{24,25}$ the cohort included infants with diverse cardiac diagnoses. As a result, the sizes of some diagnosis groups were small (eg, 1-year evaluations were conducted on 7 patients with VSD/CAVC randomized to the $\mathrm{pH}$-stat group and 9 randomized to the alpha-stat group). Overall, only $66 \%(111 / 168)$ of children enrolled in the perioperative phase of this study returned to our institution for neurodevelopmental examination at 1 year of age, although the follow-up rate was better $(84 \%)$ in the group of families identified as eligible on the basis of geographic proximity. Thus, the developmental outcome at 1 year of age may be subject to selection bias (eg, those parents most worried about their child's development might have been more likely to participate). Similarly, one or more questionnaires concerning outcome at 2 to 4 years of age were returned by only $73 \%$ of the families, despite repeated mailings. Although higher than the $60 \%$ response rate generally achieved after 3 mailings, it is possible that the respondents are not representative of the 
group enrolled. As described earlier, children for whom information on outcome is available (either inperson evaluation or parental questionnaire) were similar to children for whom no information is available. Furthermore, although selection bias may have influenced the results of the combined treatment groups, it would be unlikely to have influenced the comparison of children assigned to alpha-stat versus $\mathrm{pH}$-stat. Finally, assessments at age 1 year have relatively low predictive validity for later intelligence quotient and academic achievement, and parents' responses to developmental questionnaires can be biased or simply inaccurate.

It is of interest that the subgroup of patients with DTGA achieved significantly higher MDI scores than the subgroups of patients with TOF/other or VSD/CAVC. Although we excluded from enrollment children with congenital anomalies of more than minor severity, as well as known genetic syndromes, children were not tested for chromosomal anomalies. Microdeletion of 22q11 is known to be associated with developmental delay ${ }^{26}$ and has been reported to occur in up to $25 \%$ of patients with TOF, as well as in patients with VSD. In contrast, it has not been reported to be associated with D-TGA. ${ }^{27}$ The strikingly low mean score of the 7 patients with VSD/CAVC randomized to the $\mathrm{pH}$-stat strategy deviates widely from our usual clinical experience. We speculate that this finding might represent the chance occurrence of 22q11 microdeletion within that group of patients. In the future, routine testing of study patients for the 22q11 microdeletion would clarify the extent to which this anomaly affects the evaluation of the developmental and neurologic risks associated with particular aspects of operative management.

In summary, the type of acid-base management strategy (alpha-stat vs $\mathrm{pH}$-stat) used during reparative infant cardiac operations with deep hypothermic CPB did not have a consistent effect on neurodevelopmental outcome at 1 or 2 to 4 years of age. Children with D-TGA or TOF/other who underwent corrective operations in the earliest days of infancy tended to have better developmental outcomes if randomized to the $\mathrm{pH}$-stat strategy. In contrast, among the smaller group of patients with VSD/CAVC, who are generally operated on later in infancy, assignment to the $\mathrm{pH}$-stat strategy was associated with significantly worse outcomes. In view of the findings in the perioperative period favoring infants randomized to the $\mathrm{pH}$-stat group, we consider $\mathrm{pH}$-stat to be the generally preferable strategy for acid-base management during the cooling phase of CPB in neonates and young infants. Our data also suggest, however, that other patient and procedural factors might be more important determi- nants of neurodevelopmental outcome than acid-base management strategy during $\mathrm{CPB}$.

\section{REFERENCES}

1. Kern F, Greeley W. Pro: pH-stat management of blood gases is not preferable to alpha-stat in patients undergoing brain cooling for cardiac surgery. J Cardiothorac Vasc Anesth 1995;9:215-8.

2. Burrows F. Con: pH-stat management of blood gases is preferable to alpha-stat in patients undergoing brain cooling for cardiac surgery. J Cardiothorac Vasc Anesth 1995;9:219-21.

3. Murkin JM, Martzke JS, Buchan AM, Bentley C, Wong CJ. A randomized study of the influence of perfusion technique and $\mathrm{pH}$ management strategy in 316 patients undergoing coronary artery bypass surgery. II. Neurologic and cognitive outcomes. J Thorac Cardiovasc Surg 1995;110:349-62.

4. Wong PC, Barlow CR, Hickey PR, Jonas RA, Castaneda AR, Farrell DM, et al. Factors associated with choreoathetosis following cardiopulmonary bypass in children with congenital heart disease. Circulation 1992;86(Suppl):IV-118-26.

5. Jonas RA, Bellinger DC, Rappaport LA, Wernovsky G, Hickey PR, Farrell DM, et al. Relation of pH strategy and developmental outcome after hypothermic circulatory arrest. J Thorac Cardiovasc Surg 1993;106:362-8.

6. du Plessis AJ, Jonas RA, Wypij D, Hickey PR, Riviello J, Wessel $\mathrm{DL}$, et al. Perioperative effects of alpha-stat versus $\mathrm{pH}$-stat strategies for deep hypothermic cardiopulmonary bypass in infants. $\mathbf{J}$ Thorac Cardiovasc Surg 1997;114:991-1001.

7. Bayley N. Bayley Scales of Infant Development. New York: The Psychological Corporation; 1969.

8. Bayley N. Bayley Scales of Infant Development. 2nd ed. San Antonio (TX): The Psychological Corporation; 1993.

9. Kohen-Raz R. Scalogram analysis of some developmental sequences of infant behavior as measured by the Bayley Infant Scale of Mental Development. Genet Psych Monogr 1967;76:3-21.

10. Ireton H. The Child Development Inventory Manual. Minneapolis: Behavior Science Systems; 1992.

11. Achenbach TM. Manual for the Child Behavior Checklist/2-3 and 1992 Profile. Burlington (VT): The University of Vermont Department of Psychiatry; 1992.

12. O'Doherty N. Neurological exam of the newborn: a routine for all. Boston: MTP Press; 1986.

13. Dubowitz L, Dubowitz V. The neurological assessment of the preterm and full-term newborn infant. London: Spastics Society in association with Heinemann Medical; 1981.

14. Prechtl HFR. The neurological examination of the full term newborn infant: a manual for clinical use. 2nd ed. Oxford: Blackwell Scientific: Spastics Society in association with Heinemann Medical; 1977.

15. Paine RS, Oppe TE. Neurological examination of children. London: Spastics Society in association with Heinemann Medical; 1966.

16. Hollingshead A. Four factor index of social status. New Haven (CT): Yale University Department of Sociology; 1975.

17. Dunn L, Dunn L. The peabody picture vocabulary test: manual for forms $\mathrm{L}$ and M. Revised edition. Circle Pines (MN):American Guidance Service; 1981.

18. Benedict R. Cognitive function after open-heart surgery: Are post-operative neuropsychological deficits caused by cardiopulmonary bypass? Neuropsychol Rev 1994;4:223-55.

19. Reich DL, Uysal S, Sliwinski M, Ergin MA, Kahr RA, Konstadt $\mathrm{SN}$, et al. Neuropsychologic outcomes after deep hypothermic 
circulatory arrest in adults. J Thorac Cardiovasc Surg 1999;117:156-63.

20. Kirkham FJ. Recognition and prevention of neurological complications in pediatric cardiac surgery. Pediatr Cardiol 1998;19:33145.

21. Jonas RA. Neurological protection during cardiopulmonary bypass/deep hypothermia. Pediatr Cardiol 1998;19:321-30.

22. Aoki M, Nomura F, Stromski ME, Tsuji MK, Fackler JC, Hickey $\mathrm{PR}$, et al. Effects of $\mathrm{pH}$ on brain energetics after hypothermic circulatory arrest. Ann Thorac Surg 1993;55:1093-103.

23. Hiramatsu T, Miura T, Forbess JM, du Plessis A, Aoki M, Nomura $\mathrm{F}$, et al. $\mathrm{pH}$ strategies and cerebral energetics before and after circulatory arrest. J Thorac Cardiovasc Surg 1995;109:948-57.

24. Newburger JW, Jonas RA, Wernovsky G, Wypij D, Hickey PR,
Kuban KC, et al. A comparison of the perioperative neurologic effects of hypothermic circulatory arrest versus low-flow cardiopulmonary bypass in infant heart surgery. N Engl J Med 1993;329:1057-64.

25. Bellinger DC, Jonas RA, Rappaport LA, Wypij D, Wernovsky G, Kuban KC, et al. Developmental and neurologic status of children after heart surgery with hypothermic circulatory arrest or lowflow cardiopulmonary bypass. N Engl J Med 1995;332:549-55.

26. Moss EM, Batshaw ML, Solot CB, Gerdes M, McDonald-McGinn DM, Driscoll DA, et al. Psychoeducational profile of the 22q11.2 microdeletion: a complex pattern. J Pediatr 1999;134:193-8.

27. Goldmuntz E, Clark BJ, Mitchell LE, Jawad AF, Cuneo BF, Reed L, et al. Frequency of 22q11 deletions in patients with conotruncal defects. J Am Coll Cardiol 1998;32:492-8.

\section{Availability of Journal back issues}

As a service to our subscribers, copies of back issues of The Journal of Thoracic and Cardiovascular Surgery for the preceding 5 years are maintained and are available for purchase from Mosby until inventory is depleted. The following quantity discounts are available: $25 \%$ off on quantities of 12 to 23, and one third off on quantities of 24 or more. Please write to Mosby, Subscription Customer Service, 6277 Sea Harbor Dr, Orlando, FL 32877, or call 800-654-2452 or 407-345-4000 for information on availability of particular issues and prices. If unavailable from the publisher, photocopies of complete issues may be purchased from Bell \& Howell Information and Learning, 300 N Zeeb Rd, Ann Arbor, MI 48106-1346; 734-761-4700 or 800-521-0600. 